Scientia Agricola

http://dx.doi.org/10.1590/0103-9016-2014-0370

\title{
Assessment of sugarcane harvesting residue effects on soil spectral behavior
}

\author{
José A. M. Demattê ${ }^{1 *}$, Fabrício da Silva Terra², Rafael Otto ${ }^{1}$, Raul Shiso Toma ${ }^{3}$, Luiz Henrique Pereira ${ }^{4}$, Alexandre Ferreira do \\ Nascimento ${ }^{5}$, Marco Antonio Melo Bortoletto ${ }^{6}$
}

\author{
'University of São Paulo/ESALQ - Dept. of Soil Science, C.P. \\ 09 - 13418-260 - Piracicaba, SP - Brazil. \\ 2Federal University of Jequitinhonha and Mucuri Valleys/ \\ ICA, Av. Vereador João Narciso, 1380 - 38610-000 - Unaí, \\ MG - Brazil. \\ ${ }^{3}$ Federal University of Ceará/CCA - Dept. of Soil Sciences, \\ Av. Mister Hull, 2977 - 60356-001 - Fortaleza, CE - Brazil. \\ ${ }^{4}$ São Paulo State University/IGCE - Dept. of Territorial \\ Planning and Geoprocessing, Av. 24 A, 1515 - 13506-900 - \\ Rio Claro, SP - Brazil. \\ ${ }^{5}$ Brazilian Agricultural Research Corporation - Embrapa \\ Agrosilvopastoral, Rodovia dos Pioneiros MT-222, km 2.5 - \\ 78550-970 - Sinop, MT - Brazil. \\ ${ }^{6}$ Clealco Group S/A - GIS Division, Rodovia SP 425, km 01 - \\ 16250-000 - Clementina, SP - Brazil. \\ *Corresponding author <jamdemat@usp.br>
}

Edited by: Silvia del Carmen Imhoff

Received October 22, 2014

Accepted July 22, 2015
ABSTRACT: When the harvesting of sugarcane involves a mechanized process, plant residues remain on the soil surface, which makes proximal and remote sensing difficult to monitor. This study aimed to evaluate, under laboratory conditions, differences in the soil spectral behavior of surface layers Quartzipsamment and Hapludox soil classes due to increasing levels of sugarcane's dry (DL) and green (GL) leaf cover on the soil. Soil cover was quantified by supervised classification of the digital images (photography) taken of the treatments. The spectral reflectance of the samples was obtained using the FieldSpec Pro (350 to $2500 \mathrm{~nm}$ ). TM-Landsat bands were simulated and the Normalized Difference Vegetation Index (NDVI) and soil line were also determined. Soil cover ranged from 0 to $89 \%$ for DL and 0 to $80 \%$ for GL. Dry leaf covering affected the features of the following soil constituents: iron oxides (480, 530 and 900 $\mathrm{nm}$ ) and kaolinite (2200 nm). Water absorption (1400 and $1900 \mathrm{~nm})$ and chlorophyll (670 nm) were determinant in differentiating between bare soil and GL covering. Bands 3 and 4 and NDVI showed pronounced variations as regards differences in soil cover percentage for both $\mathrm{DL}$ and GL. The soil line allowed for discrimination of the bare soil from the covered soil (DL and GL). High resolution sensors from about $50 \%$ of the DL or GL covering are expected to reveal differences in soil spectral behavior. Above this coverage percentage, soil assessment by remote sensing is impaired.

Keywords: TM-Landsat, NDVI, soil remote sensing, soil proximal sensing, soil line

\section{Introduction}

Remote sensing of bare soils allows for determining properties of their surface horizons, such as particle distribution, mineralogy, and organic matter (Ben-Dor et al., 2009). However, this technique presents limitations due to the interference of land cover (Bartholomeus et al., 2011). Crop residues, woody stems, and forest litter on the soil surface influence soil spectral sensing and the accuracy of determining its properties. For instance, senescent vegetation and litter affect the relationship between electromagnetic radiation and soil properties, and mask a number of the spectral features, such as $\mathrm{Fe}, \mathrm{Ti}$, and $\mathrm{Al}$ oxides in the transition from red to near-infrared wavelengths (Mulder et al., 2011). The lignin/cellulose spectral feature of the crop residues affects and masks the appearance of the absorption features related to clay minerals (Galvão et al., 2001). Thus, there are many questions to be answered about how the soil cover influences the spectral signature of farming soils.

Sugarcane farming systems in the tropics have improved the soil cover because crop burning prior to harvesting was prohibited by law to be replaced by mechanized harvesting. Under this harvesting system, dry and green leaves (tips) remain on the soil surface composing the so-called "straw cover" (Oliveira et al., 1999) resulting in better soil surface energy balance, net primary productivity, nutrient cycling, and carbon sequestration in soils (Lal et al., 1999; Galdos et al., 2009). However, this has limited obtaining and recording soil spectral data mainly from aerial and orbital platforms. Hence, it becomes relevant to document the changes in the spectral behavior of soils partially or fully covered by crop residues, since this information about soil reflectance is important to professionals who use spectral data for soil survey and mapping.

This study aimed to characterize and evaluate differences in the soil spectral behavior of the surface layers of Quartzipsamment and Hapludox due to the influence of sugarcane harvesting crop residues (dry and green leaves) by reflectance spectroscopy analysis under laboratory conditions as a basis for understanding this covering effect on broader observation scales, such as the aerial and the orbital.

\section{Materials and Methods}

The study was developed in two distinct stages. The first was characterized by an analytical segment in which spectral characteristics of soils and vegetation covers were identified, analyzed, and described under laboratory conditions. The second was performed by synthesis and data integration into the computing environment. Figure 1 shows the flowchart of the methodological approach.

\section{Characterization of soils}

Considering the spatial distribution of sugarcane, samples from Hapludox (OX) and Quartzipsamment 
(ENT) soil classes were used because of their contrasting properties (Soil Survey Staff, 2010). The samples were collected from the surface layer (0-0.2 m), dried at $45{ }^{\circ} \mathrm{C}$ for $48 \mathrm{~h}$, and sieved $(2 \mathrm{~mm})$. Samples were subjected to particle size, chemical (Camargo et al, 2009) and spectral analysis (Belinaso et al., 2010). Soil properties varied widely in terms of organic matter content, cation exchange capacity (CEC), and texture (Table 1).

\section{Treatments}

The experimental design was factorial, involving soil samples from two classes (OX and ENT) and two types of plant residues: dry leaves (DL) and green leaves (GL) at different cover percentages (seven coverage lev- els for the OX and eight coverage levels for the ENT). For representation of plant residues on the ground after harvesting, green leaves were manually collected from the tip of sugarcane plants. The green leaves were immediately ground after collection (with natural moisture) in a Willey laboratory mill. Green leaves were stored in plastic bags and were sealed and kept under refrigeration at $4{ }^{\circ} \mathrm{C}$ to preserve their characteristics and avoid water loss. The DL samples (senescent leaves attached to stems) were manually collected, oven dried for $72 \mathrm{~h}$ at $65{ }^{\circ} \mathrm{C}$, and subsequently ground in a Willey laboratory mill. Grinding the samples was needed in order to adequately disperse the samples over the soil surfaces before taking measurements. However, this procedure reduces the size of plant residues when compared to the

Table 1 - Results of chemical and particle-size analyses of the Hapludox (OX) and Quartzipsamment (ENT)1.

\begin{tabular}{|c|c|c|c|c|c|c|c|c|c|c|c|c|c|}
\hline Soil & \multicolumn{2}{|c|}{$\mathrm{pH}$} & $\mathrm{SOM}^{2}$ & $\mathrm{P}$ & K & $\mathrm{Ca}$ & $\mathrm{Mg}$ & Al & $\mathrm{H}+\mathrm{Al}$ & $\mathrm{SB}^{3}$ & $\mathrm{CEC}^{4}$ & $\mathrm{BS}^{5}$ & Texture $^{6}$ \\
\hline & $\mathrm{H}_{2} \mathrm{O}$ & $\mathrm{KCl}$ & $\mathrm{g} \mathrm{kg}^{-1}$ & $\mathrm{mg} \mathrm{kg}^{-1}$ & & & & $-m$ & -1 & & & $\%$ & \\
\hline $0 X$ & 5.2 & 4.3 & 33 & 18 & 1.7 & 29 & 17 & 5 & 60 & 47.7 & 107.7 & 44 & Heavy clay \\
\hline ENT & 5.1 & 4.6 & 5 & 2 & 0.1 & 2 & 1 & 4 & 8 & 3.1 & 11.1 & 28 & Sandy \\
\hline
\end{tabular}

${ }^{1}$ Chemical analyses according to Raij et al. (2001) and particle size analysis according to Camargo et al. (2009); ${ }^{2}$ SOM: soil organic matter; ${ }^{3 S B}$ : Sum of exchangeable bases ${ }^{4} \mathrm{CEC}$ : cation exchange capacity; ${ }^{5}$ : base saturation; ${ }^{6}$ Heavy clay: clay content $>60 \%$; sandy: clay content $<15 \%$ (EMBRAPA, 2006).

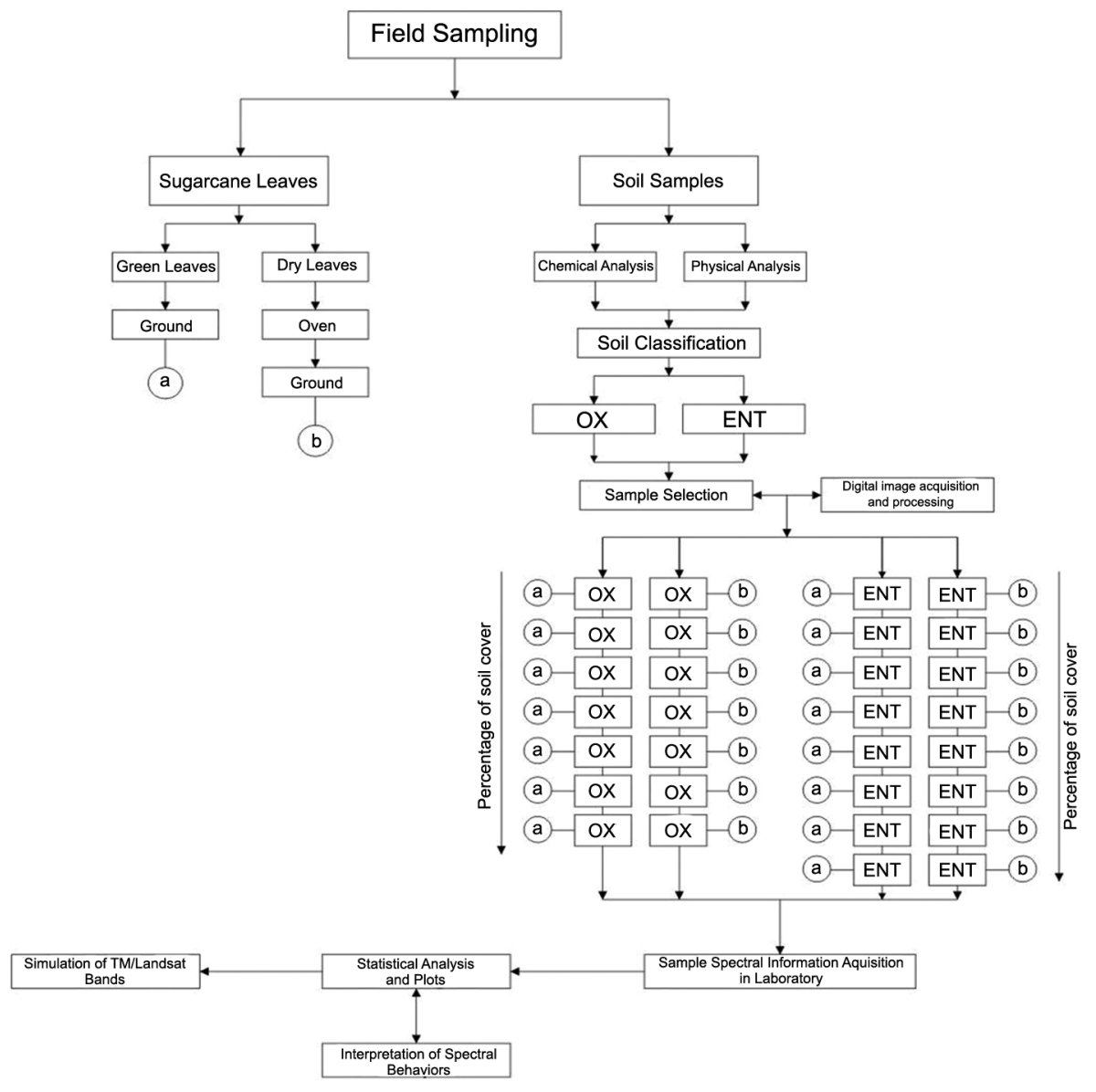

Figure 1 - Flowchart of the methodological procedures. 
real scale where the size of the leaves normally left on the soil surface after harvesting is bigger. Without doubt, this factor can have an impact on comparisons of our results with others obtained under field conditions.

Increasing levels of finely ground residues were added over the soil samples placed in Petri dishes with 90-mm internal diameter. Coverage gradients ranged from bare to soils completely covered with both plant residues. The cover gradient was based on the weight of the leaves which ranged from 0 to $0.26 \mathrm{~g}_{\text {container }}{ }^{-1}$ for DL (dry basis) and 0 to $0.80 \mathrm{~g}^{\text {container }}{ }^{-1}$ for GL (moisture basis) since these materials presented different densities. An additional treatment was included in both soil types with surfaces completely covered with their respective plant materials. Three dishes were used for each treatment to represent each repetition.

\section{Ground cover percentage}

To quantify the percentage of plant residue (DL and GL) coverage of the total area of each soil sample, supervised classification of the digital image was adopted as shown in Figure 2 and detailed as follows: firstly, a digital image of each sample was recorded by a camera (SONY cyber-shot 7.2 MP) which was vertically positioned (nadir axis) above each dish placed on a black and opaque background. The distance between camera and surface of sample was $0.3 \mathrm{~m}$ corresponding to a field of view around $2 \mathrm{~mm}^{2}$. Such geometry allowed for the same spatial dimensions and resolutions between images to facilitate comparisons. Secondly, the digital images were processed using appropriate software for the elements of interest in the soil samples to be classified and quantified. To avoid uncertainties in classification and quantification, a useful area on the center of the sample (boundary rectangle) was defined over which the RGBIHS (intensity-hue-saturation) transformation was applied to highlight the contrast between elements. Transformed images were segmented and classified using the Gaussian Maximum Likelihood algorithm (Richards and
Jia, 1999). Three thematic classes were chosen: vegetation (dry leaves and green leaves), soil, and shadow. Confusion matrices (or contingency table, or error matrix) were used to validate the classifications by crossing the classified pixels with the previously selected sample pixels. Coverage percentages of each thematic class for each soil sample were also determined.

\section{Reflectance spectroscopy analyses}

Reflectance data were obtained under laboratory conditions using a FieldSpec Pro (ASD, 1999) spectroradiometer with a spectral resolution of $1 \mathrm{~nm}$ from 350 to $1100 \mathrm{~nm}$ and of $2 \mathrm{~nm}$ from 1100 to $2500 \mathrm{~nm}$. The geometry of data acquisition was in agreement with Bellinaso et al. (2010) where the probe was vertically positioned 8 $\mathrm{cm}$ above the sample and the light source (halogen bulb $50 \mathrm{~W})$ at $35 \mathrm{~cm}$ with a $30^{\circ}$ zenith angle. A white plate of barium sulfate (spectralon) with $100 \%$ of reflectance was used as a reference standard. Spectral behavior of each treatment was obtained by the graphical representation of the reflectance values along wavelengths.

\section{Assessment of spectral data}

For interpretation of the spectral data, the following procedures were used: (a) analogical comparison: based on the qualitative description of the spectral properties, such as absorption features, reflectance intensity and shape of spectra by comparing with pre-existing standards (Demattê et al., 2012; Demattê and Terra, 2014); (b) first derivative: used to enhance and identify the position of absorption features (Scheinost et al., 1998), and (C) principal component analysis (PCA): used to reduce the data dimensionality and provide clustering of samples based on spectral similarity (Galvão et al., 1995).

The spectral data obtained in the laboratory were used in the convolution and simulation of the TM/ LANDSAT 5 sensor bands and determination of NDVI (Tucker, 1979) to evaluate their sensitivity under influ-

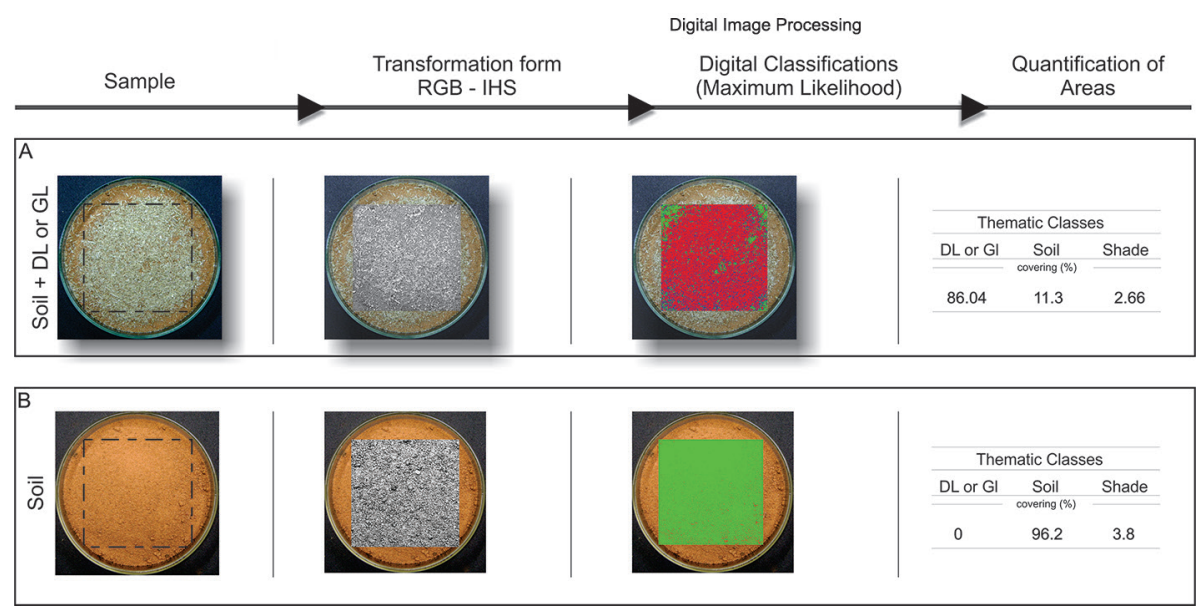

Figure 2 - Procedure for digital image classification and quantifying of soil cover: A) dry or green leaves (DL / GL) and shade, and B) exposed soil and shade. 
ence of vegetation cover variation aiming future orbital applications in soil evaluation. Average values of reflectance from the spectroradiometer were calculated according to the TM sensor bands, i.e., 450-520 nm (band 1), $520-600 \mathrm{~nm}$ (band 2), 630-690 nm (band 3), 760-900 nm (band 4), 1550-1750 nm (band 5) and 2080-2350 nm (band 7). The soil line was also determined in order to evaluate the spectral ratio applied in the analysis of surface variations for multispectral data (Baret et al., 1993). This ratio is based on the relationship between the reflectance data of the spectral bands corresponding to the red (band 3) and near-infrared (band 4) wavelengths.

\section{Results and Discussion}

\section{Percentage of soil coverage}

For the OX, the percentage of DL cover ranged from 0 to $89 \%$ and with GL cover from 0 to $80 \%$, while for the ENT, the DL cover ranged from 0 to 84 $\%$ and with GL from 0 to $77 \%$ (Table 2). Even in treatments where the soil surface was completely covered with plant residues, coverage did not reach $100 \%$ due to the occurrence of shadow which significantly changes the spectral behavior of a target. For this reason, it was considered in our study. The percentage of shadow was higher for GL than for DL due to a greater material overlap due to higher moisture in GL.

\section{Influence of plant coverage on soil spectral behavior} Covering with DL and GL influenced the spectral behavior of soils changing shape, absorption features, and, principally, reflectance intensity along the spectra (Figure 3). The ENT soil with sandy texture have presented higher reflectance intensities along the spectrum in relation to the OX soil, predominantly heavy clay, as also observed by Galvão et al., (2001) and Nanni and Demattê (2006). Regardless of soil and cover type, the reflectance intensity of spectra increased following the increment of soil coverage by plant residues, suggesting more reflected electromagnetic energy. In the OX, this effect was more evident; since, when exposed, it reflected lower energy due to its mineralogical constitution. The influence of different cover levels can be better defined in heavy clay than in sandy soils.
Increasing levels of plant residues also affected typical absorption features of soil constituents. In the Figures 3 and 4, we observed that the cover with DL masked the features of goethite and hematite at $480 \mathrm{~nm}$ (1) and $530 \mathrm{~nm}$ (2), respectively (Sherman and Waite, 1985), total iron oxides at $900 \mathrm{~nm}$ (3) (Stoner et al., 1980), hydroxyls of 2:1 and 1:1 clay minerals and structural soil water at $1400 \mathrm{~nm} \mathrm{(4)} \mathrm{and} 1900 \mathrm{~nm}$ (5), respectively, and aluminol group of $2: 1$ and 1:1 clay minerals at $2200 \mathrm{~nm}$ (6) (Hunt and Salislury, 1970; Stoner and Baumgardner, 1981). Additionally, the smallest amount of water still remaining in the dry leaves (oven dried at $65^{\circ} \mathrm{C}$ ) provided absorption peaks at $1450 \mathrm{~nm}(7)$, shifted to the right side of the soil feature, and also at $1900 \mathrm{~nm}$. The masking of GL in the soil spectral behavior occurred in a similar way, but due to the influence of green cover, the spectra showed absorption features very characteristic of chlorophyll at $670 \mathrm{~nm} \mathrm{(8)} \mathrm{and} \mathrm{water} \mathrm{at} 1450$ and $1900 \mathrm{~nm}$ (Fortes and Demattê, 2006) allowing for easy differentiation between bare and covered soil. It was not possible to identify the absorption features of nitrogen $(\mathrm{N})$ in green vegetation since these features have been masked by strong water absorption bands (Kokaly and Clark, 1999).

These results corroborate Collins (1978), who observed changes in the spectral shape and intensity caused by changes in the composition and structure of cells throughout the different developmental stages of vegetation. The more advanced the phenological stage, the more the information changes, especially in the visible spectral range where linearity and attenuation of the curve features occur in the region between 400 and 690 $\mathrm{nm}$.

The chlorophyll absorption feature at $670 \mathrm{~nm}$ (Fortes and Demattê, 2006) enabled the best differentiation between soil covered with GL and soil covered with DL, as indicated by feature 8 in the Figures 3 and 4. Changes in plant spectral behavior in the visible region occur due to the decreased activity of chlorophyll-a and chlorophyll-b (Mulders, 1987). The performance of these two types of chlorophyll can be observed in the GL spectra at two small absorbance peaks around $640 \mathrm{~nm}$ (9), conditioned by chlorophyll-b, and $670 \mathrm{~nm}$, caused

Table 2 - Percentage of soil covering with different rates of covering by dry or green leaves of sugarcane.

\begin{tabular}{|c|c|c|c|c|c|c|c|c|}
\hline \multirow[t]{2}{*}{ Treatment } & \multicolumn{8}{|c|}{ Covering rate } \\
\hline & 1 & 2 & 3 & 4 & 5 & 6 & 7 & 8 \\
\hline & & & & - Soil c & $\lg (\%)^{1}$ & +2 & 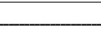 & +2 \\
\hline \multicolumn{9}{|l|}{ Hapludox } \\
\hline Dry leaves & $0(14)$ & $9(10)$ & $15(11)$ & 27 (18) & $50(20)$ & $67(11)$ & 89 (11) & - \\
\hline Green leaves & $0(13)$ & $9(22)$ & $13(18)$ & $26(20)$ & $51(21)$ & $67(20)$ & $80(20)$ & - \\
\hline \multicolumn{9}{|c|}{ Quartzipsamment } \\
\hline Dry leaves & $0(10)$ & $6(12)$ & $12(14)$ & $18(12)$ & $31(07)$ & $52(08)$ & 74 (19) & 84 (16) \\
\hline Green leaves & $0(05)$ & $7(15)$ & 14 (19) & 18 (16) & $23(12)$ & $51(10)$ & 70 (19) & 77 (23) \\
\hline
\end{tabular}

${ }^{1}$ values between brackets refer to shade influence. Percentage of bare soil can be obtained by $100-(\%$ soil covering $+\%$ of shade). 
A

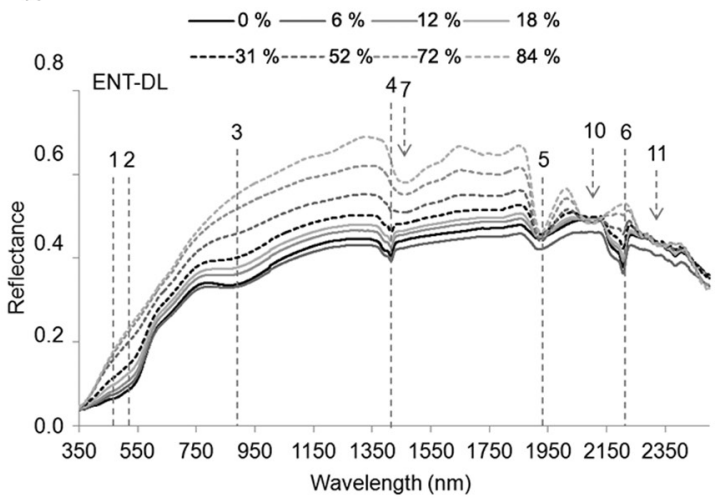

B

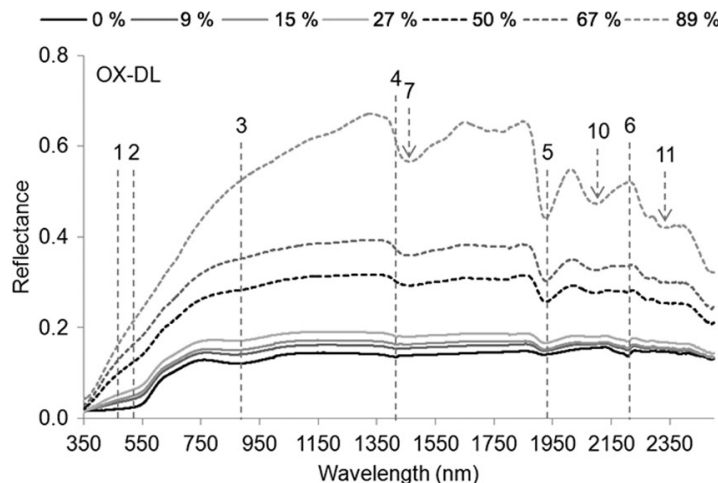

C

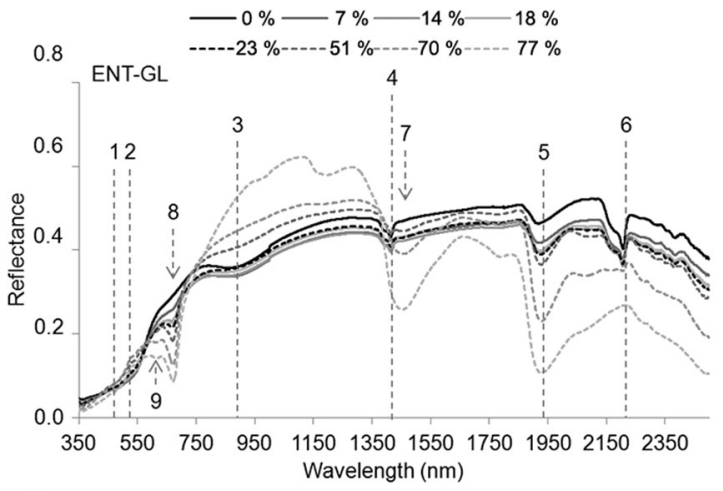

D

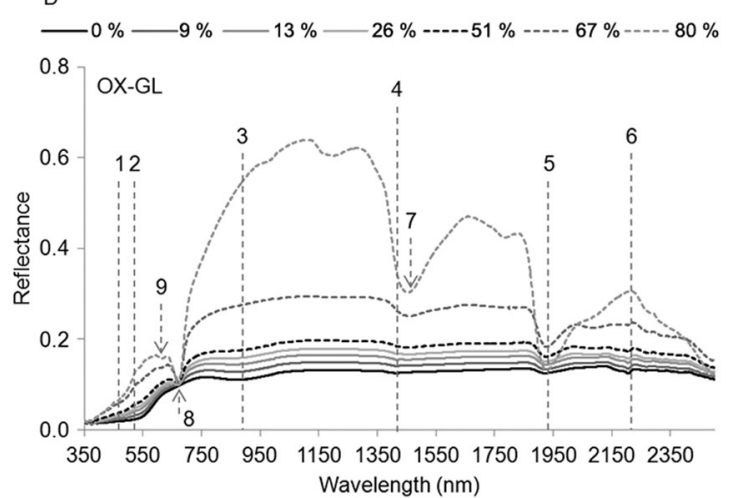

Figure 3 - Spectral behaviors of the Quartzipsamment (ENT) and Hapludox (OX) with different soil covering by dry (DL) or green leaves (GL) of sugarcane. The percentage of soil covering is shown in the legend. Absorption features were numbered as follows: (1) goethite, (2) hematite, (3) total iron oxides, hydroxyls, (4) 2:1 and 1:1 clay minerals, (5) structural soil water, (6) aluminol group of 2:1 and 1:1 clay minerals, (7) remaining water in the dry leaves, (8) chlorophyll-a, (9) chlorophyll-b, (10) lignin, and (11) cellulose.

by chlorophyll-a. Larcher (1995) highlights that the ratio of chlorophyll-a to chlorophyll-b in plants is around 3:1, which explains the stronger reflectance in the region of $670 \mathrm{~nm}$ (Figures 3 and 4).

During the phenological development, the reflectance intensity in these spectral bands loses its characteristics due to the decreasing activity of chlorophyll, and changes occur in the plant morphology and physiology, which leads to changes in features at near-infrared wavelengths (Mulders, 1987). In this spectral range, a more evident absorption peaks at $2100 \mathrm{~nm} \mathrm{(10)} \mathrm{and}$ at $2300 \mathrm{~nm}$ (11) were more evident in the DL than in the GL (Figures 3 and 4). Vegetation coverage exerts a spectral influence on the soil masking the absorption due to aluminol group of $2: 1$ and $1: 1$ clay minerals at $2200 \mathrm{~nm}$ by features of lignin and cellulose at 2100 and $2300 \mathrm{~nm}$, respectively, thereby making detection of this mineral constituent more difficult in this range. However, these characteristics take into account the homogeneous distribution of finely ground materials on the soil surface, and when the plant canopy is considered, the reflectance spectrum starts to be influenced by factors such as leaf area, percentage of soil cover, soil reflectance and optical properties of leaves (Rudorff and Batista, 1991).

\section{Principal Component Analysis (PCA)}

PCA allowed clustering treatments according to their spectral characteristics, as indicated by Galvão et al. (2001) (Figure 5). The first component (PC1) represented $95 \%$ of the total variance of the spectral data and was directly related to the reflectance intensity of the samples. The second component (PC2), related to the spectral shape due to the absorption features showed 4 $\%$ of the spectra variance. The dispersion between the first two principal components allowed for distinguishing the following clusters: 1- OX with DL and GL cover below $30 \%$; 2- ENT with GL and DL cover below $30 \%$; 3- OX and ENT with DL cover above $80 \%$; and 4- OX and ENT with GL cover above $75 \%$. Samples with intermediate values of coverage were intermediately positioned in the clusters indicating an influence of gradual increment of green and dry leaves in both soils in the approach to these four clusters (Figure 5).

The points related to the full coverage by both GL and DL were separately positioned in the scattergram of the PCA environment, since they have the same plant material but at different phenological stages with differences in characteristics such as spatial orientation of canopies, conditions of cell structure, and distribution of shadows. 

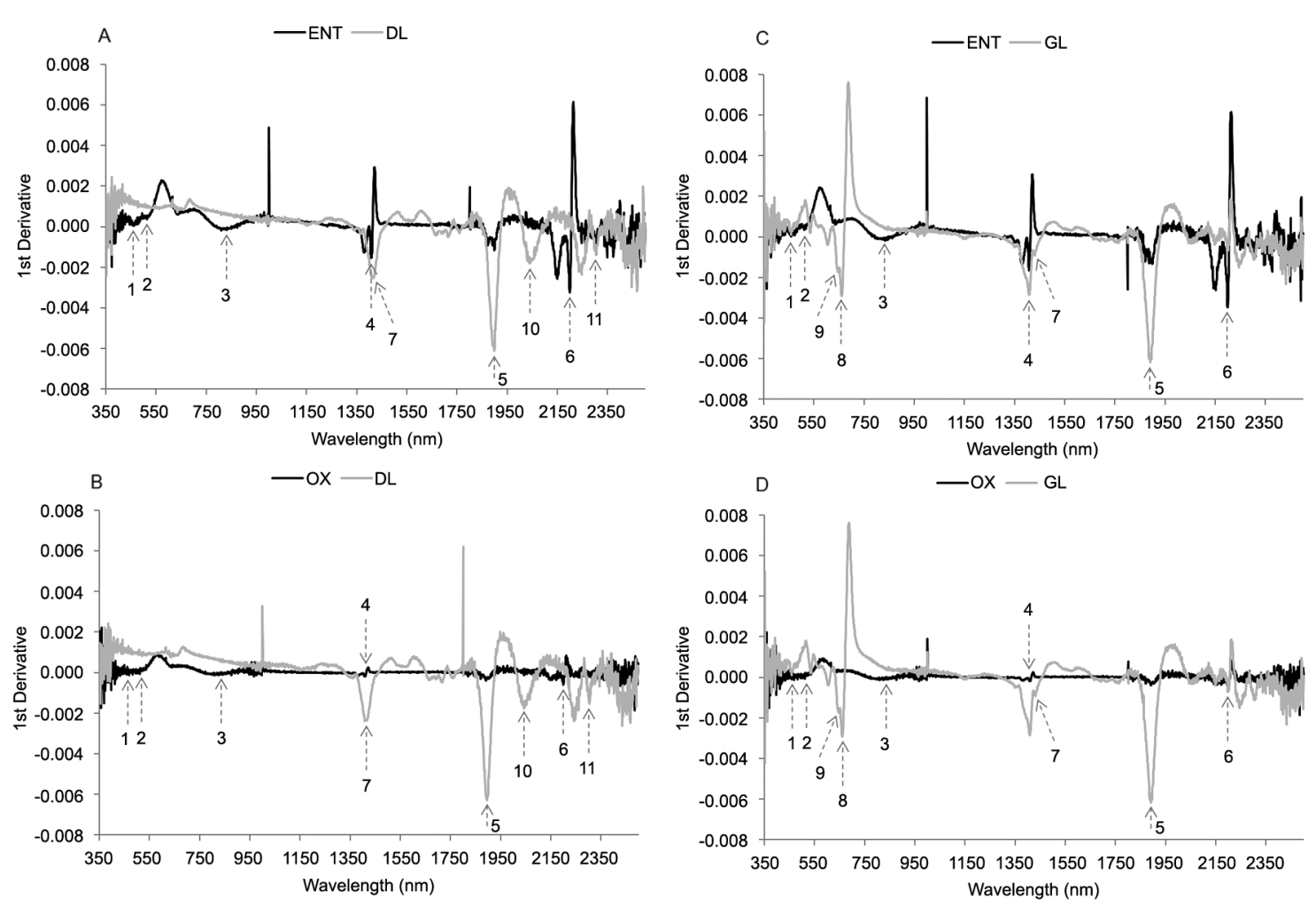

Figure 4 - First derivate of the soil spectral behavior (Quartzipsamment - ENT and Hapludox - OX) without and with total covering by dry (DL) or green leaves (GL) of sugarcane. Absorption features were numbered as follows: (1) goethite, (2) hematite, (3) total iron oxides, hydroxyls of (4) 2:1 and 1:1 clay minerals and (5) structural soil water, (6) aluminol group of 2:1 and 1:1 clay minerals, (7) remaining water in the dry leaves, (8) chlorophyll-a, (9) chlorophyll-b, (10) lignin, and (11) cellulose.

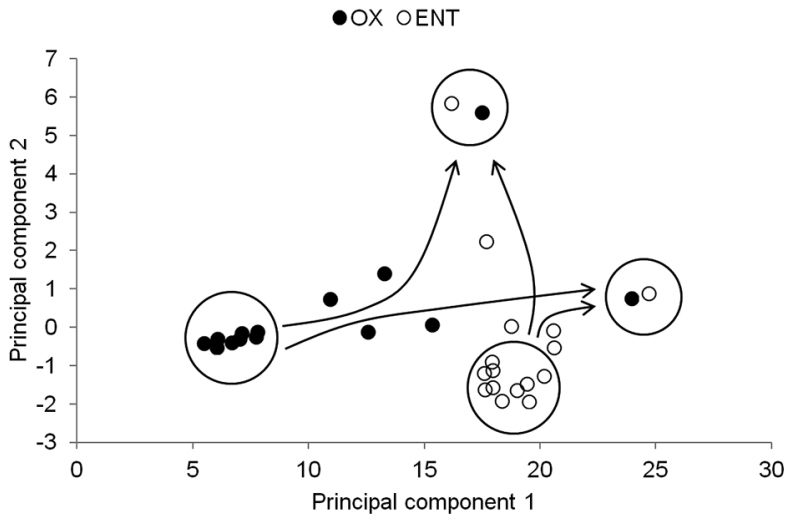

Figure 5 - Diagram of principal component scores of Quartzipsamment (ENT) and Hapludox (OX) with varied levels of cover by dry and green leaves of sugarcane.

\section{Sensitivity of TM-Landsat bands and NDVI in the identification of soil cover}

For the OX soil, all TM-Landsat simulated bands showed relationships at all percentages of soil cover with GL and DL (Table 3). For the ENT soil, bands 1, 2, 3, 4, and 5 appropriately indicated soil cover with DL, while bands 3,4 , and 7 were more sensitive in identifying cover with GL. Overall, there was an average increase in reflectance with the increment of soil coverage by plant materials. However, an inverse relationship was identified for the ENT covered by GL where the average reflectance of bands $2,3,5$, and 7 decreased as soil cover increased. This occurs because the reflectance intensity of bare ENT soil is naturally higher when compared to OX soil, and it was gradually influenced by the GL addition on the soil surface where that reflectance begins to decrease from 1300 $\mathrm{nm}$ due to the influence of the spectral behavior of green leaves (Figure 3). This influence was not observed for the OX, which naturally has lower reflectance intensities along the wavelengths due to its properties, as already described.

Our results are in accordance with the main applications of bands 1 and 4 of the LANDSAT satellite. Band 1 ranging from 450 to $520 \mathrm{~nm}$ was used to differentiate soil from vegetation and was sensitive to coverage of green and dry leaves on the OX and ENT soils. When the soils were covered by green leaves, the band 4 ranging from 760 to $900 \mathrm{~nm}$ used to monitor biomass was sensitive to differentiating between them.

Band 7 of the Landsat has shown good results in monitoring plant residues on soil, once it has allowed for identifying the presence of lignin and cellulose not present in soil (Gelder et al., 2009). However, in this study band 7 was less sensitive in differentiating soil and vege- 
Demattê et al.

Soil cover effects on soil spectra

Table 3 - Spectral reflectance for the simulated bands of the TM-Landsat and NDVI indices for both soils with different rates of soil covering by dry or green leaves of sugarcane.

\begin{tabular}{|c|c|c|c|c|c|c|c|}
\hline \multirow{2}{*}{ Soil covering (\%) } & \multicolumn{6}{|c|}{ Bands TM-LANDSAT } & \multirow{2}{*}{$\mathrm{NDVI}$} \\
\hline & $(1)$ & (2) & (3) & (4) & (5) & (7) & \\
\hline Hapludox & & & 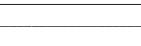 & Dry leaves & & & 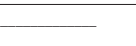 \\
\hline 0 & 0.022 & 0.043 & 0.104 & 0.124 & 0.143 & 0.149 & 0.088 \\
\hline 9 & 0.038 & 0.061 & 0.119 & 0.143 & 0.160 & 0.157 & 0.091 \\
\hline 15 & 0.044 & 0.068 & 0.125 & 0.151 & 0.169 & 0.161 & 0.095 \\
\hline 27 & 0.056 & 0.083 & 0.142 & 0.172 & 0.186 & 0.174 & 0.096 \\
\hline 50 & 0.108 & 0.149 & 0.218 & 0.277 & 0.307 & 0.272 & 0.119 \\
\hline 67 & 0.141 & 0.191 & 0.265 & 0.342 & 0.379 & 0.323 & 0.126 \\
\hline 89 & 0.181 & 0.252 & 0.347 & 0.492 & 0.635 & 0.475 & 0.173 \\
\hline$p<$ & 0.01 & 0.01 & 0.01 & 0.01 & 0.01 & 0.01 & 0.01 \\
\hline $\mathrm{R}^{2}$ & 99.32 (RL) & 99.05 (RL) & $98.27(\mathrm{RL})$ & $96.02(\mathrm{RL})$ & $90.77(\mathrm{RL})$ & 93.72 (RL) & $90.00(\mathrm{RL})$ \\
\hline 0 & 0.020 & 0.039 & 0.094 & $\begin{array}{l}\text { Green leaves - } \\
0.113\end{array}$ & 0.131 & 0.133 & 0.092 \\
\hline 9 & 0.026 & 0.048 & 0.099 & 0.129 & 0.146 & 0.142 & 0.134 \\
\hline 13 & 0.037 & 0.064 & 0.105 & 0.158 & 0.173 & 0.161 & 0.199 \\
\hline 26 & 0.043 & 0.074 & 0.110 & 0.173 & 0.189 & 0.175 & 0.220 \\
\hline 51 & 0.069 & 0.118 & 0.131 & 0.266 & 0.272 & 0.224 & 0.341 \\
\hline 67 & 0.081 & 0.140 & 0.136 & 0.330 & 0.333 & 0.256 & 0.418 \\
\hline 80 & 0.082 & 0.150 & 0.135 & 0.482 & 0.448 & 0.270 & 0.561 \\
\hline$p<$ & 0.01 & 0.01 & 0.01 & 0.01 & 0.01 & 0.01 & 0.01 \\
\hline $\mathrm{R}^{2}$ & $97.25(\mathrm{RL})$ & $99.00(\mathrm{RL})$ & $95.63(\mathrm{RL})$ & $92.83(\mathrm{RL})$ & $95.07(\mathrm{RL})$ & $99.32(\mathrm{RL})$ & $97.08(\mathrm{RL})$ \\
\hline Quartzipsamment & & & & - Dry leaves - & & & 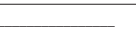 \\
\hline 0 & 0.071 & 0.137 & 0.267 & 0.338 & 0.463 & 0.448 & 0.116 \\
\hline 6 & 0.083 & 0.148 & 0.270 & 0.341 & 0.459 & 0.435 & 0.117 \\
\hline 12 & 0.091 & 0.158 & 0.283 & 0.359 & 0.479 & 0.452 & 0.119 \\
\hline 18 & 0.107 & 0.174 & 0.294 & 0.373 & 0.490 & 0.455 & 0.119 \\
\hline 31 & 0.125 & 0.192 & 0.309 & 0.394 & 0.510 & 0.464 & 0.121 \\
\hline 52 & 0.160 & 0.224 & 0.322 & 0.421 & 0.524 & 0.450 & 0.133 \\
\hline 72 & 0.172 & 0.236 & 0.329 & 0.435 & 0.525 & 0.435 & 0.139 \\
\hline 84 & 0.198 & 0.272 & 0.369 & 0.518 & 0.649 & 0.483 & 0.167 \\
\hline$p<$ & 0.01 & 0.01 & 0.01 & 0.01 & 0.01 & 0.05 & 0.01 \\
\hline $\mathrm{R}^{2}$ & 98.52 (RL) & 98.20 (RL) & $93.56(\mathrm{RL})$ & 92.11 (RL) & 77.26 (RL) & 15.18 (RL) & 84.59 (RL) \\
\hline 0 & 0.076 & 0.142 & 0.283 & $\begin{array}{l}\text { - Green leaves - } \\
0.360\end{array}$ & 0.495 & 0.475 & 0.119 \\
\hline 7 & 0.074 & 0.138 & 0.255 & 0.337 & 0.455 & 0.431 & 0.138 \\
\hline 14 & 0.076 & 0.140 & 0.234 & 0.339 & 0.448 & 0.411 & 0.184 \\
\hline 18 & 0.077 & 0.141 & 0.233 & 0.346 & 0.460 & 0.420 & 0.195 \\
\hline 23 & 0.080 & 0.144 & 0.225 & 0.351 & 0.459 & 0.413 & 0.218 \\
\hline 51 & 0.091 & 0.160 & 0.207 & 0.392 & 0.483 & 0.408 & 0.308 \\
\hline 70 & 0.093 & 0.163 & 0.162 & 0.419 & 0.466 & 0.339 & 0.443 \\
\hline 77 & 0.074 & 0.136 & 0.121 & 0.458 & 0.409 & 0.235 & 0.582 \\
\hline$p<$ & 0.01 & 0.05 & 0.01 & 0.01 & 0.01 & 0.01 & 0.01 \\
\hline $\mathrm{R}^{2}$ & $49.76(\mathrm{RQ})$ & $28.61(\mathrm{RQ})$ & $92.44(\mathrm{RL})$ & 86.70 (RL) & $20.53(\mathrm{RL})$ & $77.78(\mathrm{RL})$ & $94.22(\mathrm{RL})$ \\
\hline
\end{tabular}

$\mathrm{RL}=$ linear regression; $\mathrm{RQ}=$ quadratic regression.

tation, especially for the ENT soil. Bands 3 and 4 presented a consistent and significant increasing of reflectance intensity conditioned by the increment of soil coverage, suggesting that both bands can be used to discriminate soils covered by these plant materials. Therefore, spectral indices using reflectance values from bands 3 and 4, such as the NDVI, have the potential to differentiate soils covered by residues of sugarcane crop.
The NDVI was used to identify the threshold at which the soil spectral behavior begins to be particularly influenced by vegetation (Figure 6). As soil cover increased, an increase in the NDVI was observed for both soils and both plant residues, though more pronounced for GL (Table 3). The NDVI represents the distance between bands 4 (reflectance attributed to the structural characteristics of plants) and 3 (energy absorbed by pho- 


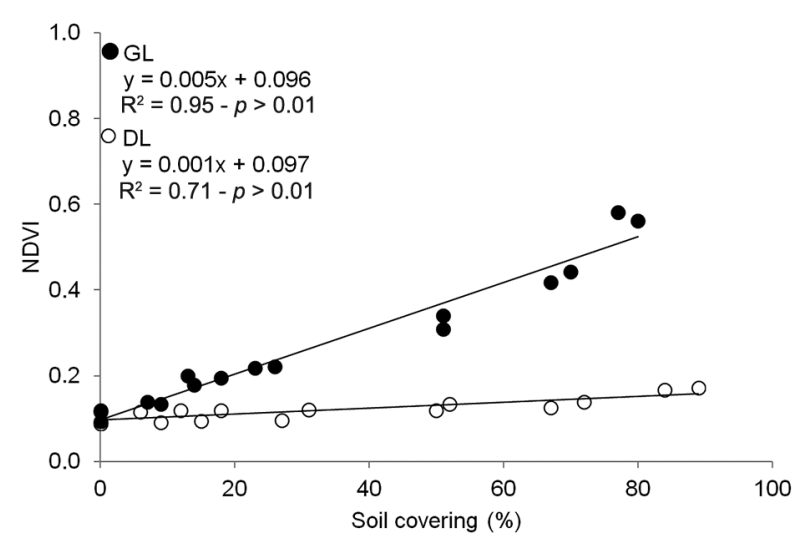

Figure 6 - Scatter diagram showing the relationship between the Normalized Difference Vegetation Index (NDVI) index and percentage of soil covering by dry (DL) or green leaves (GL) of sugarcane.

tosynthesis), and this distance tends to decrease following increases in the dry matter content, as observed in this study. The NDVI was significantly correlated with the soil cover in the OX and ENT for both GL and DL (Table 3). However the index allowed for clearer differentiation in soil covered by GL than by DL due to the greater contrast between the green leaves and the soils. Given that the average NDVI for sugarcane has ranged from 0.69 to 0.78 (Fortes and Demattê, 2006), this index can be used as a parameter to distinguish areas cultivated with sugarcane from areas already harvested or areas with crop residues on soil, since the values observed were lower than 0.17 for soil covered by DL and lower than 0.58 for soil covered by GL (Table 3 and Figure 6).

Attempts to measure crop residue cover using remotely sensed data have had mixed success (Mulder et al., 2011). In areas having strongly contrasting soil and residue reflectance, Landsat TM-based indices such as the simple ratio-type vegetation indices (SRTVI) and normalized difference-type vegetation indices (NDTVI) successfully identified broad crop residue classes for cover ranging from small plots up to $1500 \mathrm{~km}^{2}$ (Serbin et al., 2009). However, these indices were less effective when used in regions with different soil types because of the poor contrasts between crop residues and soils (Qi et al., 2002). This poor performance was partly ascribed to the broadness of the Landsat TM bands, which are unable to discriminate absorptions of specific materials ranging from the 1000 to the $2500 \mathrm{~nm}$ wavelength (Mirik et al., 2005). According to Mulder et al. (2011), future studies need to focus on improved integration of proximal and remote sensing using scaling based approaches in order to make optimal use of all data sources available.

\section{Soil Line}

Based on the ratio between red and infrared bands, the soil line allowed for separating OX and ENT soil with different levels of coverage as well as the soils

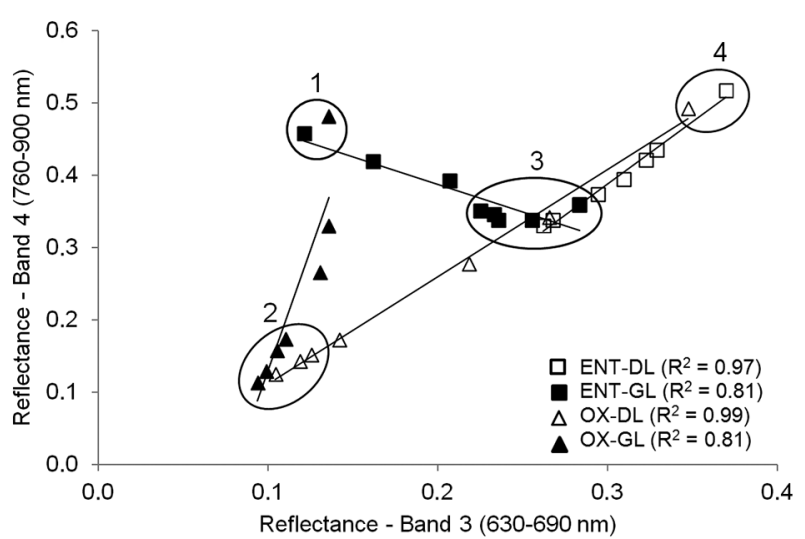

Figure 7 - Soil line of both soil samples (ENT and OX) with varied cover by dry (DL) or green leaves (GL) of sugarcane. Clusters: 1soil covered with GL, 2- OX with little or no cover, 3- ENT with little or no cover, and 4- soil covered with DL.

fully covered by DL and GL (Figure 7). The bare OX was positioned at the lower left corner due to the low reflectance values in bands 3 and 4 (cluster 2). On the other hand, the bare ENT which presented higher reflectance values in both bands was located at the central position, corroborating Demattê et al. (2004). Treatments with full coverage by GL were positioned at the upper left corner (cluster 1) because of increased vegetation reflectance and absorbance at band 4 and 3, respectively. The treatments with total DL cover (cluster 4) were positioned in the upper right corner due to high reflectance in bands 3 and 4 . As the soil cover percentage increased, a displacement of treatments beginning from the bare soil clusters (2 and 3 ) toward the clusters dominated by the plant coverage ( 1 and 4 ) was observed, demonstrating the contribution and influence of spectral behavior of vegetation on the reflectance data regardless of the level of coverage.

When considered individually, the soil line can mislead in differentiating the bare ENT soil from intermediate levels of DL covering the OX soil. This highlights the importance of simultaneous evaluation of the soil line position and spectral behavior (shape, intensity, and features), as emphasized by Demattê et al. (2004). The assessment of soil spectral behavior has allowed for differentiation of sandy soils with low iron contents from heavy clay soils with high iron contents (Galvão et al., 2001; Nanni and Demattê, 2006), such as those evaluated in this study, which help in the differentiation of bare soils and soils covered by plant residues.

\section{Conclusions}

The crop residue of sugarcane harvesting (green and dry leaves) on the ground changes the spectral behavior of sandy and heavy clay soils where plant residues mask typical absorption features of soil mineralo- 
gy such as: goethite (480 nm), hematite (530 nm), total iron (900 nm), and kaolinite (2200 nm). Soils covered by green leaves (GL) can be easily differentiated from soils covered with dry leaves (DL) by analyzing the absorption peak of chlorophyll (670 $\mathrm{nm}$ ) and water (1400 and $1900 \mathrm{~nm}$ ) in the spectra. Spectra of soils begin to undergo modification after about $50 \%$ of soil covering by GL and DL of sugarcane. When the soil coverage is less than $50 \%$, spectral characteristics of the soil is still possible to detected. Principal Component Analysis enables sandy and heavy clay soils to be distinguished with different levels of coverage by dry and green leaves of sugarcane due to differences in reflectance intensities, absorption features, and spectral shapes.

When using simulated multispectral data, bands 3 (red) and 4 (near-infrared) of TM-Landsat and the NDVI are the most appropriate spectral information to effectively quantify the percentage of soil cover with plant residues (DL and GL). The NDVI allows for differentiating areas cropped with sugarcane where the harvesting has been performed in a raw-cane system with maintenance of residues on the soil surface. The soil line is also effective for distinguishing soils with different levels of vegetation cover by DL and GL, as well as soils with different particle size and mineralogy. However, a simultaneous assessment of the soil line position and spectral behavior of the target is recommended to avoid confusion when discriminating bare sandy soils from soils covered by dry plant residues.

\section{References}

Analytical Spectral Devices [ASD]. 1999. ASD Technical Guide. 3ed. ASD, Boulder, CO, USA

Baret, F.; Jacquemoud, S.; Hanocq, J.F. 1993. The soil line concept in remote sensing. Remote Sensing of Environment 7: 11-18.

Bartholomeus, H.; Kooistra, L.; Stevens, A.; Leeuwen, M. van; Wesemael, B. van; Ben-Dor, E.; Tychon, B. 2011. Soil organic carbon mapping of partially vegetated agricultural fields with imaging spectroscopy. International Journal of Applied Earth Observation and Geoinformation 13: 81-88.

Bellinaso, H.; Demattê, J.A.M.; Romeiro, S.A. 2010. Soil spectral library and its use in soil classification. Revista Brasileira de Ciência do Solo 34: 861-870.

Ben-Dor, E.; Chabrillat, S.; Demattê, J.A.M.; Taylor, G.R.; Hill, J.; Whiting, M.L.; Sommer, S. 2009. Using imaging spectroscopy to study soil properties. Remote Sensing of Environment 113: S38-S55.

Collins, W. 1978: Remote sensing of crop type and maturity. Photogrammetric Engineering and Remote Sensing 44: 4355.

Demattê, J.A.M.; Terra, F.S. 2014. Spectral Pedology: a new perspective on evaluation of soils along pedogenetic alterations. Geoderma 217: 190-200.

Demattê, J.A.M.; Terra, F.S.; Quartaroli, C.F. 2012. Spectral behavior of some modal soil profiles from São Paulo state, Brazil. Bragantia 71: 413-423.
Demattê, J.A.M.; Toledo, A.M.A.; Simões, M.S. 2004. Methodology for the recognition of three soils by using laboratory and orbital sensors. Revista Brasileira de Ciência do Solo 28: 877-889.

Fortes, C.; Demattê, J.A.M. 2006. Discrimination of sugarcane varieties using Landsat $7 \mathrm{ETM}+$ spectral data. International Journal of Remote Sensing 27: 1395-1412.

Galdos, M.V.; Cerri, C.C.; Cerri, C.E.P. 2009. Soil carbon stocks under burned and unburned sugarcane in Brazil. Geoderma 153: 347-352.

Galvão, L.S.; Pizarro, M.A.; Epiphanio, J.C.N. 2001. Variations in reflectance of tropical soil: spectral-chemical compositions relationships from AVIRIS data. Remote Sensing of Environment 75: 245-255.

Galvão, L.S.; Vitorello, I.; Paradella, W.R. 1995. Spectroradiometric discrimination of laterites with principal components analysis and additive modeling. Remote Sensing of Environment 53: 70-75.

Gelder, B.K.; Kaleita, A.L.; Cruse, R.M. 2009. Estimating mean field residue cover on midwestern soils using satellite imagery. Agronomy Journal 101: 635-643.

Hunt, G.R.; Salisbury, J.W. 1970. Visible and near-red spectra of minerals and rocks. I. Silicate minerals. Modern Geology 1: 283-300.

Kokaly, R.F.; Clark, R.N. 1999. Spectroscopic determination of leaf biochemistry using band-depth analysis of absorption features and stepwise multiple linear regression. Remote Sensing of Environment 67: 267-287.

Lal, R.; Kimble, J.M.; Follett, R.F.; Cole, C.V. 1999. The Potential of Us Cropland to Sequester Carbon and Mitigate the Greenhouse Effect. Lewis Publishers, Boca Ratón, FL, USA.

Larcher, W. 1995. Physiological Plant Ecology: Ecophysiology and Stress Physiology of Functional Groups. Springer, Berlin, Germany.

Mirik, M.; Norland, J.E.; Crabtree, R.L.; Biondini, M.E. 2005. Hyperspectral one-meter resolution remote sensing in Yellow Stone Park Wyoming. II. Biomass. Rangeland Ecology and Management 58: 459-466.

Mulder, V.L.; Bruin, S.; Schaepman, M.E.; Mayr, T.R. 2011. The use of remote sensing in soil and terrain mapping: a review. Geoderma 162: 1-19.

Mulders, M.A. 1987. Remote Sensing in Soil Science. Elsevier, Nova York, NY, USA.

Nanni, M.R.; Demattê, J.A.M. 2006. Soil line behavior obtained by laboratorial spectroradiometry for different soil classes. Revista Brasileira de Ciência do Solo 30: 1031-1038 (in Portuguese, with abstract in English).

Oliveira, M.W.; Trivelin, P.C.O.; Penatti, C.P.; Piccolo, M.C. 1999. Field decomposition and release of sugar cane trash nutrients. Pesquisa Agropecuária Brasileira 34: 2359-2362 (in Portuguese, with abstract in English).

Qi, J.; Marsett, R.; Heilman, P.; Biedenbender, S.; Moran, S.M.; Goodrich, D. 2002. Ranges improves satellite-based information and land cover assessments in the Southwest United States. Eos, Transactions, American Geophysical Union 83: 601-606.

Richards, J.A.; Jia, X. 1999. Remote Sensing Digital Image Analysis. Springer, New York, NY, USA.

Rudorff, B.F.T.; Batista, G.T. 1991. Wheat yield estimation at the farm level using TM Landsat and agrometeorological data. International Journal of Remote Sensing 12: 2477-2484. 
Scheinost, A.C.; Chavernas, A.; Barron, V.; Torrent, J. 1998. Use and limitations of second-derivative diffuse reflectance spectroscopy in the visible to near-infrared range to identify and quantify $\mathrm{Fe}$ oxide minerals in soils. Clays and Clay Minerals 46: 528-536.

Serbin, G.; Daughtry, C.S.T.; Hunt, E.R.; Brown, D.J.; McCarty, G.W. 2009. Effects of soil composition and mineralogy on remote sensing of crop residue cover. Remote Sensing of Environment 113: 224-238.

Sherman, D.M.; Waite, T.D. 1985. Electronic spectra of Fe oxides and oxide hydroxides in the near IR to near UV. American Mineralogist 70: 1262-1269.
Soil Survey Staff. 2010. Keys to Soil Taxonomy. 11ed. USDANRCS, Washington, DC, USA.

Stoner, E.R.; Baumgardner, M.F. 1981. Characteristics variations in reflectance of surface soils. Soil Science Society of America Journal 45: 1161-1165.

Stoner, E.R.; Baumgardner, M.F.; Biehl, L.L.; Robinson, B.F. 1980. Atlas of Soil Reflectance Properties. Laboratory for Application of Remote Sensing, Purdue University, West Lafayette, IN, USA. (Research Bulletin, 962).

Tucker, C.J. 1979. Red and photographic infrared linear combinations for monitoring vegetation. Remote Sensing of Environment 8: 127-150. 